\title{
Description of a new genus and species of miniature monacanthid fish from the Seychelles and Marshall Islands
}

\author{
J. B. Hutchins \\ Department of Aquatic Zoology, Western Australian Museum, \\ Francis Street, Perth, Western Australia 6000, Australia
}

\begin{abstract}
A new genus and species of monacanthid fish, Enigmacanthus filamentosus, is described from three specimens, one from the Seychelles in the Indian Ocean and two from the Marshall Islands in the Pacific. It is characterised by the structure and positioning of its epineural ribs (distal extremities branched or expanded, ribs commencing on the third abdominal vertebra). The new taxon has no apparent close relatives, but appears most similar to Paramonacanthus, particularly in body shape. However, it lacks the distinctively elevated soft dorsal and anal fins in the male of Paramonacanthus, as well as having no sexual dimorphism of the osteological structures supporting these fins. Like members of the monacanthid genera Rudarius and Acreichthys, the new taxon matures at sizes smaller than $30 \mathrm{~mm} \mathrm{SL}$, and may be categorised as another miniature representative of the family.
\end{abstract}

\section{INTRODUCTION}

Monacanthids have often been described on the basis of small to minute specimens. Most of these have turned out to represent the juvenile form of species that grow considerably larger (e.g. Monacanthus nitens Hollard, 1854, holotype $41 \mathrm{~mm}$ in standard length (SL) = Pervagor janthinosoma Bleeker, 1854, maximum size $113 \mathrm{~mm} \mathrm{SL}$; Monacanthus peroni Hollard, 1854, holotype $45 \mathrm{~mm}$ $\mathrm{SL}=$ Pseudomonacanthus peroni, maximum size 350 $\mathrm{mm} \mathrm{SL}$; and Brachaluteres taylori Woods, 1966, holotype $14 \mathrm{~mm} \mathrm{SL}=B$. taylori, maximum size 50 mm SL). Tyler (1970) was the first to describe a truly minute monacanthid, Rudarius minutus, which is sexually mature at only $17 \mathrm{~mm}$ SL. Hutchins (1977) subsequently presented a description of an even smaller species, Rudarius excelsus, which reaches sexual maturity at $15 \mathrm{~mm}$ SL. In their redescription of Acreichthys radiatus (Popta, 1900), Tyler and Lange (1982) reported mature specimens as small as $20 \mathrm{~mm}$ SL. The purpose of the present paper is to describe as new another miniature monacanthid which achieves maturity at sizes less than $30 \mathrm{~mm}$ SL. Although new, descriptions of this species have appeared before, but taxonomic confusion has masked its true identity.

Fraser-Brunner (1940), in his revision of the monacanthid genus Stephanolepis, provided the first description of this species under the name Stephanolepis freycineti. He believed that his small specimen from the Seychelles (BMNH 1908.3.23.294, $36 \mathrm{~mm} \mathrm{SL}$, originally reported in a list by Regan [1908] as Monacanthus setifer Bennett) represented a species first described from Mauritius by Quoy and Gaimard (1824) as Balistes freycineti. Unfortunately, a subsequent examination by the present author of the type of Balistes freycineti (MNHN A.4100, 178 $\mathrm{mm} \mathrm{SL)} \mathrm{showed} \mathrm{that} \mathrm{it} \mathrm{is} \mathrm{a} \mathrm{member} \mathrm{of} \mathrm{the}$ Australian genus Meuschenia with a distribution restricted to southern Australia (Hutchins, 1977). As reported by Whitley (1943), the collections of Quoy and Gaimard-which included material from both Mauritius and Australia-were on board the "L'Uranie" when it was shipwrecked in the Falkland Islands in 1820 . These were saved and eventually conducted to France, but not before some of the material was apparently mixed up. Whitley (1943), for example, reported on the atherinid Atherina jacksoniana; this was described by Quoy and Gaimard (1824) from a specimen supposedly collected in Sydney Harbour but in fact was from South America. Also the description of Balistes hippocrepis Quoy and Gaimard, 1824 was based on an Australian specimen and not an example from Mauritius as stated. Therefore, the fish from the Seychelles that was presented as Stephanolepis freycineti by Fraser-Brunner cannot be the species described by Quoy and Gaimard.

Some twenty-five years later, Woods (1966) provided a detailed description of a pair of monacanthids from the Marshall Islands in the Pacific under the earlier name of Paramonacanthus oblongus (Schlegel, 1850). Woods believed his small (27-35 $\mathrm{mm}$ SL) specimens represented immature individuals of that species.

As part of an investigation on the systematics of the family by the present author (Hutchins, 1988), 
the three specimens of Fraser-Brunner and Woods were re-examined. They were all found to represent an undescribed genus and species, and were placed in the phylogenetic suprageneric category referred to as Group A (this contains all monacanthids that possess a movably articulated pelvic fin rudiment, see Hutchins, 1997). A description of the new taxon is presented below, and includes a discussion of its apparent relationships with other members of the family.

Methods of counting and measuring follow those of Hutchins (1977, 1986), whereas terminology follows Hutchins (1997). The term "epineural rib" may be better stated as "epineural bone" (A.C. Gill, pers. comm.), but this is not followed here. Abbreviations for institutions are recorded in the acknowledgements.

\section{SYSTEMATICS}

\section{Family Monacanthidae Nardo}

\section{Genus Enigmacanthus gen. nov.}

\section{Type species}

Enigmacanthus filamentosus sp. nov. (see below).

\section{Diagnosis}

Distinguished from all other Group A genera (i.e., those possessing a pelvic fin rudiment movably articulated with the pelvis) of Hutchins (1988) by the structure and positioning of its epineural ribs. These ribs possess branched or expanded distal extremities, and commence on the third abdominal vertebra (all other Group A genera have epineural ribs with unexpanded extremities that, with the exception of Colurodontis and two species of Paramonacanthus, commence on the second abdominal vertebra). Other distinctive characters are given in the species diagnosis presented below.

\section{Relationships}

Hutchins (1988) was able to find only one derived character to separate this genus (referred to by Hutchins as "Genus b") from other genera in his Group A category. This entailed the branched or expanded distal extremities of the epineural ribs, a feature shared with one Group B genus (Aluterus) and several Group C genera (Rudarius, Brachaluteres, and Paraluteres) (see Hutchins, 1997 for a list of genera belonging to Groups A, B, and C). All other monacanthids have unexpanded extremities. He surmised that this derived condition evolved independently in the three lineages involved. Another derived state concerning the positioning of the epineural ribs (commencing on the third abdominal vertebra versus the second abdominal vertebra) is also shared with Colurodontis and two species of Paramonacanthus, all from Group A; however this apparent synapomorphy is not supported by other shared derived characters (see remarks section in species account below).

Enigmacanthus is most similar to Paramonacanthus in body shape, but lacks the anteriorly elevated soft dorsal and anal fins that characterise the latter genus (Hutchins, 1997). Its scalation is quite different from Stephanolepis (scale spinules are not supported by a broad-based pedicle, and there are no mandibular sensory scales in the lateral line sensory system, features that distinguish Stephanolepis from all other monacanthids), but it shares some characters with Pervagor (scale spinules more robust, positioned along a transverse ridge, and one species of Pervagor possesses 1-2 elongate filamentous rays in the soft dorsal fin); however the characteristic deep caudal peduncle, robust first dorsal spine and robust pelvic fin rudiment (see Hutchins, 1986) of the latter genus are not present in Enigmacanthus. The monotypic Colurodontis also possesses a deep caudal peduncle (male condition only), and has two uniquely derived characters (very slender pelvis, and internal tusks in the lower jaw) that are not present in Enigmacanthus. The lack of clear-cut synapomorphies makes it difficult to decide whether any of these taxa are closely related to this new genus.

\section{Etymology}

Enigmacanthus is formed from "enigma" (meaning puzzling) and "acanthus" (the stem of numerous monacanthid genera). It refers to the unresolved relationships between this genus and other monacanthid taxa. The gender is masculine.

\section{Enigmacanthus filamentosus sp. nov.} Figures 1, 2 and 3; Table 1

Monacanthus setifer (non Bennett, 1830): Regan, 1908: 252

Stephanolepis freycineti (non Quoy and Gaimard, 1824): Fraser-Brunner, 1940: 523, figure

Paramonacanthus oblongus (non Schlegel, 1850): Woods 1966: 90 , plate $133 \mathrm{~b}$.

"Genus b species 1" Hutchins, 1988: 380, figures 15, $80,129,340,395$.

"Genus b" Hutchins, 1994: 568

\section{Holotype}

USNM 140642, $35 \mathrm{~mm}$ SL, male, Marshall Islands (Pacific Ocean), Rongelap Atoll, lagoon $3 \mathrm{~km} \mathrm{~W}$ of Bush Island, dredge at $36 \mathrm{~m}, 21$ June 1946 (S-46232).

\section{Paratypes}

USNM 361255, $27 \mathrm{~mm}$ SL, female (cleared and stained), collected with holotype; BMNH 


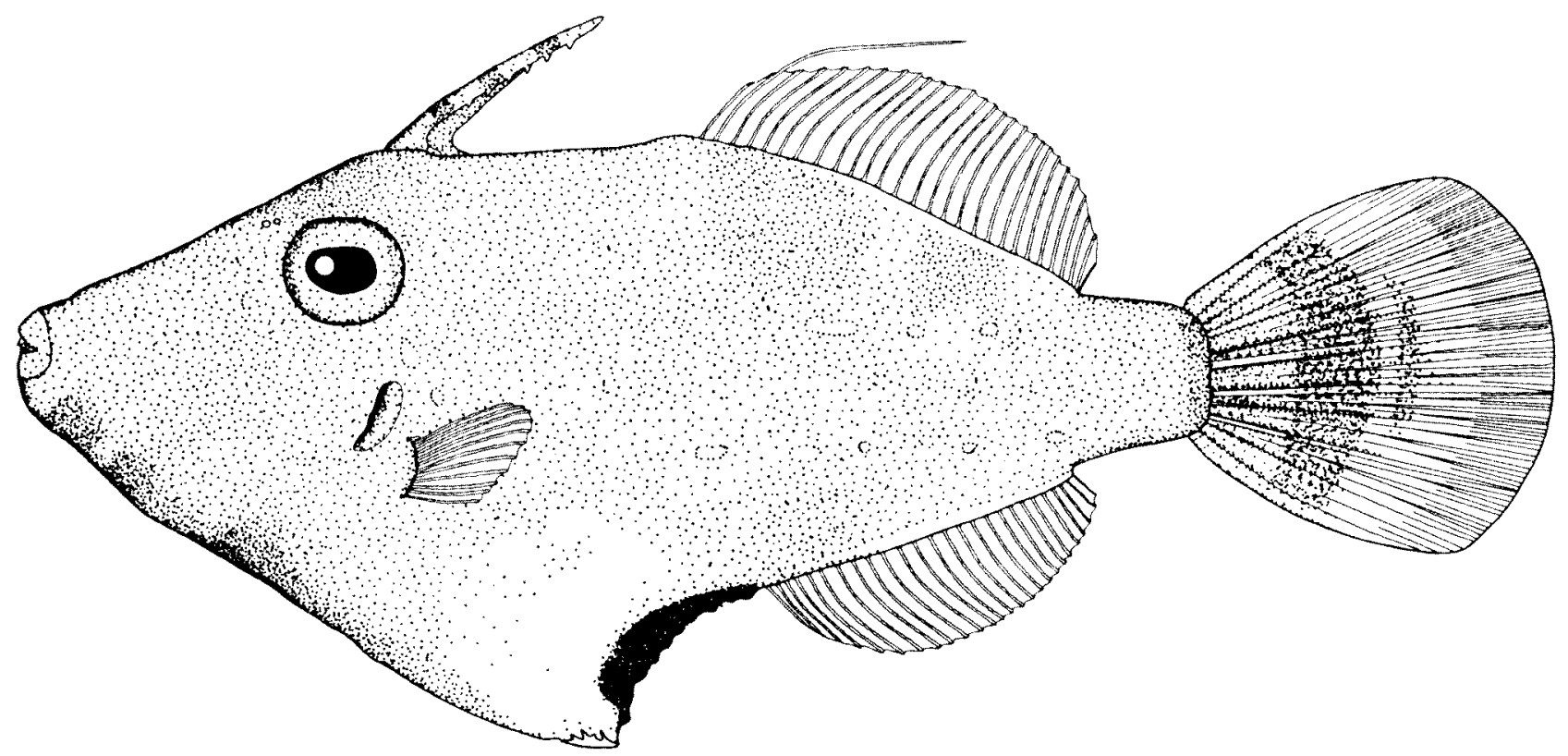

Figure 1 Enigmacanthus filamentosus, holotype, USNM 140642, $35 \mathrm{~mm} \mathrm{SL}$, male, Marshall Islands (colour pattern markings based on the photograph of Woods, 1966]).

1908.3.23:294, $36 \mathrm{~mm}$ SL, male, Seychelles, Gardiner Collection, $67 \mathrm{~m}$, no other data.

\section{Diagnosis}

A monacanthid with the following combination of characters: maximum known size small $(36 \mathrm{~mm}$ $\mathrm{SL}$ ); soft dorsal rays $27-28$; anal rays 26 ; pectoral rays $11 / 11$; dorsal profile of snout straight in male (Figure 1), slightly concave in female, without prominent hump just before nostrils; soft dorsal and anal fins not elevated anteriorly, outer margins convex; soft dorsal fin of male with second ray elongate and filamentous (damaged in both male specimens); caudal fin moderately long (about equal to head length), posterior margin convex; pelvis capable of moving vertically through an arc of about 40 degrees, producing a moderately large ventral flap; lobe on rear of pelvis small, directed dorsoposteriorly; pelvic fin rudiment relatively short and small, posterior segment movably articulated with pelvis; midbody scales each with up to six minute spinules located on a transverse ridge, those on caudal peduncle of male slightly longer, recurved, forming a poorly defined patch of bristles.

\section{Description}

Measurements of the holotype and paratypes are presented in Table 1. The following counts and proportions in parentheses represent the ranges for the paratypes when they differ from those of the holotype.

Soft dorsal rays 28 (27-28); anal rays 26; pectoral rays $11 / 11$; vertebrae $7+12=19$ (from radiographs and cleared and stained material); vertebral column of male paratype deflected ventrally, presumably the result of a deformity; branchiostegals $1+4=5$.

Body compressed and rather elongate, noticeably deeper in female, width $2.5(1.8-2.2)$ in head length

Table 1 Fin ray counts and morphometrics of Enigmacanthus filamentosus

\begin{tabular}{ccc}
\hline Holotype & Paratype & Paratype \\
USNM & USNM & BMNH \\
140642 & 361255 & $1908.3 .23: 294$
\end{tabular}

\begin{tabular}{lccc}
\hline Standard length & 35 & 27 & 36 \\
Head length & 12 & 9.8 & 12 \\
Body depth & 14 & 13 & 12 \\
Body width & 4.7 & 4.5 & 6.6 \\
Snout length & 7.9 & 6.8 & 8.3 \\
Eye diameter & 3.9 & 3.2 & 3.7 \\
Interorbital width & 3.3 & 3.1 & 4.0 \\
Gill slit length & 1.7 & $\#$ & 1.8 \\
Snout to dorsal spine & 12 & $\#$ & 12 \\
Lower jaw to PFR & 22 & $\#$ & 25 \\
Dorsal spine length & 7.8 & 7.2 & $7.2^{*}$ \\
Interdorsal space & 8.5 & 7.2 & 10 \\
Longest dorsal ray & 4.1 & $\#$ & $3.6^{*}$ \\
Longest anal ray & 3.6 & $\#$ & $4.1^{*}$ \\
Longest pectoral ray & 3.1 & $\#$ & $3.8^{*}$ \\
Length of caudal fin & 12 & $\#$ & $12^{*}$ \\
Length of dorsal fin base & 12 & 9.2 & 12 \\
Length of anal fin base & 10 & 7.9 & 11 \\
Length of caudal peduncle & 3.3 & 1.8 & 3.2 \\
Depth of caudal peduncle & 4.1 & 2.7 & 4.6 \\
Length of PFR & 1.6 & 1.4 & 1.7 \\
Soft dorsal fin ray count & 28 & 27 & 28 \\
Anal fin ray count & 26 & 26 & 26 \\
Pectoral fin ray count & 11,11 & 11,11 & 11,11 \\
Sex & Male & Female & Male \\
\hline
\end{tabular}

\# Measurement not taken due to damage

* Measurement affected by distortion/damage 
and depth 2.5 (2.1-3.0) in SL; head rather long, length $2.9(2.8-3.0)$ in SL; dorsal profile of snout when viewed laterally straight to slightly concave, more concave in female, length $4.4(4.0-4.3)$ in $\mathrm{SL}$; eye diameter 3.1 (3.1-3.2) in head length, 0.8 (1.01.1) in interorbital width; gill opening a short slit, length 7.1 (6.7) in head length, positioned in advance of pectoral fin base, centred below posterior quarter of eye; pelvic flap relatively moderate in size, posterior margin of flap broadly joined to pelvic fin rudiment.

Mouth small, terminal, lips not obviously fleshy; dentition consisting of three outer and two inner teeth on each side of upper jaw (exposed portion of both inner teeth small but obvious); three teeth on each side of lower jaw, posterior tooth very small; anterior pair of teeth in both jaws with pointed extremities.

First dorsal spine originating over posterior third of eye to slightly in advance of rear border; spine moderately long, length 1.5 (1.4) in head length, somewhat circular in cross-section, tapering to acute tip; smallest specimen available (female paratype, $27 \mathrm{~mm} \mathrm{SL}$ ) with four rows of barbs on dorsal spine, two adjacent rows of double-branched barbs on anterior face, downward directed branch prominent in middle of spine, but upward-directed branch strongest on proximal and distal portions (Figure 2), and two rows of larger, downwarddirected barbs on posterior face, projecting mostly posterolaterally; in largest specimen (male paratype, $36 \mathrm{~mm} \mathrm{SL}$ ) anterior series of barbs worn but still visible, posterior series with some barbs double branched, downward-directed one strongest; posterior barbs support relatively long, branched tentacles, some anterior barbs with small, simple tentacles; second dorsal spine small, hidden in skin at rear base of first spine; shallow groove in interdorsal space for receiving first dorsal spine when folded rearwards; soft dorsal and anal fins not elevated anteriorly, profile of outer margin of fins convex in both sexes, although second ray of dorsal fin of male prominently elongate and filamentous (damaged in holotype and paratype); longest non-filamentous dorsal ray 2.9 in head length, slightly longer than longest anal ray; length of soft dorsal base $2.9(2.9-3.0)$ in SL, slightly longer than anal base, length $3.5(3.3-3.4)$ in SL; bases of fin membranes not perforated; origin of soft dorsal well in advance of anal fin origin; interdorsal space slightly greater than length of first dorsal spine in adult (equal in female paratype), profile between fins flat to slightly elevated in male, slightly more elevated in female; base of pectoral fin below a point ranging from slightly behind rear border of eye to slightly in advance of rear border; caudal fin moderately long, length in male equal to head length, with convex posterior margin; caudal peduncle slightly tapered, length $3.6(3.8-5.4)$ in head length, $1.2(1.4-1.5)$ in caudal peduncle depth; pelvic fin rudiment (Figure 3 ) relatively small in size, length 2.4 (2.2-2.3) in eye diameter, consisting of five encasing scales with small barbs and spinules, an anterior pair (segment 1), a middle pair (segment 2), and a single posterior scale (segment 3 ); scales of segment 2 separated from each other

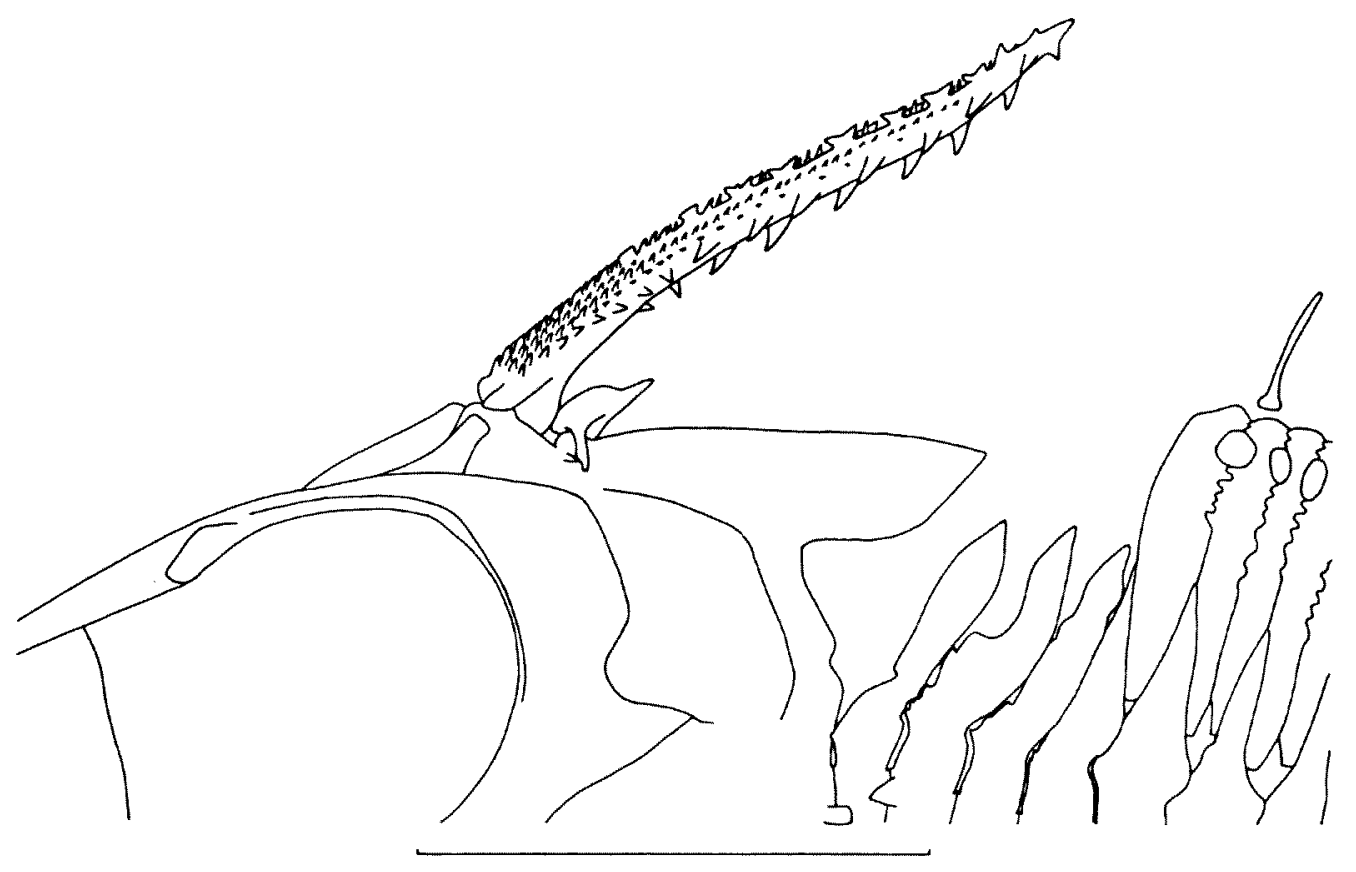

Figure 2 Diagram of portion of the skull and vertebral column of Enigmacanthus filamentosus, paratype, USNM 361255, $27 \mathrm{~mm} \mathrm{SL}$, female, showing structure of first dorsal spine and predorsal neural spines (anterior end faces left; horizontal line represents $5 \mathrm{~mm}$ ). 


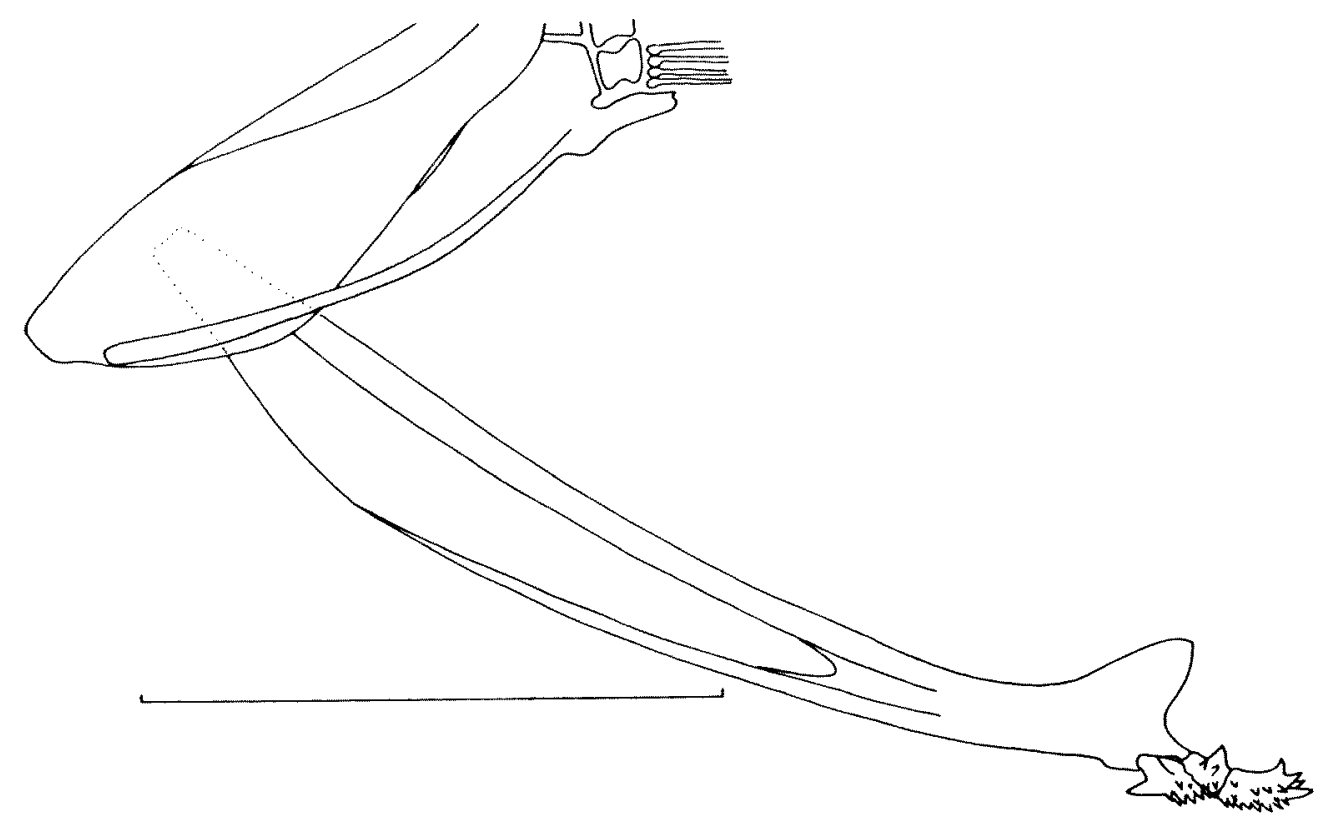

Figure 3 Diagram of portion of the pelvic/pectoral region of Enigmacanthus filamentosus, paratype, USNM 361255, 27 $\mathrm{mm} \mathrm{SL}$, female, showing shape and structure of pelvis and pelvic fin rudiment (anterior end faces left; horizontal line represents $5 \mathrm{~mm}$ ).

along ventral midline of rudiment by a prominent gap as in the monacanthid genus Lalmohania (see Hutchins 1994, figure 3); segment 3 movably articulated with both segment 2 and rear end of pelvis; pelvic fin rudiment broadly joined to posterior margin of ventral flap (Figure 1).

Midbody scales of cleared and stained female paratype small, imbricate, elliptical in shape, each with three spinules, middle one somewhat stronger, distal extremities curving posteriorly, supported by a transverse, somewhat $\mathrm{v}$-shaped ridge, acute portion directed anteriorly; scales slightly larger on caudal peduncle; male holotype with up to six spinules arranged transversely along a ridge on each midbody scale, some spinules directed anteriorly; spinules on caudal peduncle slightly longer, distal extremities curving anteriorly, forming a poorly defined patch of short bristles (some scales on posterior half of peduncle with only a single bristle); scales on forehead and breast enlarged, circular and more robust, with numerous short robust spinules; skin velvety to slightly coarse; relatively large, multibranched cutaneous tentacles on body.

Colour of holotype in alcohol: ground colour pale brown, fins and ventral flap more translucent to hyaline; ventral profile from lower jaw to just anterior to pelvic fin rudiment mostly brownish, forming three darker cross-bars (Figure 1); ventral flap pale, with prominent dusky posterior margin; posterior portion of caudal peduncle brownish; median portion of caudal fin with indications of 1-2 curved dusky cross bars. The male paratype from the Seychelles has 3 broad longitudinal stripes on the side of the body, in addition to the markings described for the holotype (also see following colour description).

Colour in life is unknown, but the following description (shortened and modified) from Woods (1966) of preserved male and female specimensthe present holotype and one paratype-from the Marshall Islands presents some clues (Figure 1): ground colour light brown, throat and breast crossed by 2-3 indistinct bars; base of soft dorsal and anal fins each with 2 large brown blotches; series of white dots running obliquely from eye, beneath pectoral fin to belly; 4-5 incomplete horizontal rows of small white spots on sides; ventral flap with dark brown or black posterior margin; dorsal spine with 3 dark brown cross bars, membrane dusky; soft dorsal and anal fins colourless; caudal fin pale, dusky at base, with series of transverse spots and bars on middle of fin giving appearance of a blackish cross bar. The preserved male specimen from the Seychelles (second paratype) was described and figured by Fraser-Brunner (1940: figure 1) as having 3 broad longitudinal stripes on the side of the body, a blackish area along the ventral surface from mouth to pelvic fin rudiment, a dusky posterior margin to the ventral flap, and a caudal fin with a broad median band and 4 submarginal bands, membranes with longitudinal series of carmine spots.

\section{Etymology}

This species is named filamentosus in reference to the filamentous second ray in the male's soft dorsal fin. 


\section{Distribution}

Enigmacanthus filamentosus is known only from the Marshall Islands in the Pacific and the Seychelles in the Indian Ocean.

\section{Remarks}

Enigmacanthus filamentosus is a very small species that apparently inhabits sandy bottoms in depths between 36 and $67 \mathrm{~m}$. It is probably widely distributed across insular areas of the Indo-West Pacific but has remained largely undetected because of its size and depths of habitation. Its strong scale spinules on the dorsal and ventral surfaces of the head, like those found on coral reef dwellers such as members of Pervagor, Amanses, and Oxymonacanthus, suggest that it inhabits coral areas. However, as it was dredged from soft substrates, perhaps it favours scattered coral clumps on the sandy bottoms of deep lagoons.

Enigmacanthus is one of four monacanthid genera that possess an elongate filamentous ray in the soft dorsal fin (Stephanolepis, Paramonacanthus, and Pervagor are the other three). It is most similar in general appearance to Paramonacanthus, particularly two species from the Western Indian Ocean, $P$. frenatus and $P$. nematophorus. It differs from these two in the following ways: 1) lacks elevated soft dorsal and anal fin rays anteriorly in the male, 2) the osteology of the underlying pterygiophores supporting the elongated rays is different (the male does not develop enlarged interpterygiophore spaces, see Hutchins, 1997), 3) it lacks the characteristic dark streak on the anal fin of the male, 4) it only has one foramen in the basal pterygiophore of the spinous dorsal fin instead of two, 5) the pelvis is more elongate with a much smaller dorsal flange, and 6) scale spinules are more robust in Enigmacanthus. In addition, this species does not appear to form schools, unlike all species of Paramonacanthus.

\section{Additional material examined}

Meuschenia freycineti, MNHN A.4100, $178 \mathrm{~mm} \mathrm{SL,}$ holotype of Balistes freycineti, "Ile Maurice" (should be Australia, see above), Quoy and Gaimard; Meuschenia hippocrepis, MHNH B.2015, $250 \mathrm{~mm} \mathrm{SL,}$ holotype of Balistes hippocrepis, "Ile Maurice" (should be Australia, see above), Quoy and Gaimard.

\section{ACKNOWLEDGEMENTS}

I wish to thank A.C. Wheeler and A.C. Gill of the Natural History Museum, London (BMNH) and M.-L. Bauchot of the Muséum National d'Histoire
Naturelle, Paris (MNHN) for the loan of specimens and providing information. My wife, Anne, capably prepared the translations of several foreign papers. Finally, I would like to acknowledge the assistance provided by S.M. Morrison of the Western Australian Museum, Perth (WAM) during the period of this study.

\section{REFERENCES}

Bennett, E.T. (1830). Observations on a collection of fishes, formed during the voyage of H.M.S. "Chanticleer", with the characters of two new species. Proceedings of the Zoological Society of London 1: 112.

Bleeker, P. (1854). Vijfde bijdrage tot de kennis der ichthylogische fauna van Amboina. Natuurkundig Tijdschrift voor Nederlandsch Indië 6: 455-508

Fraser-Brunner, A. (1940). Notes on the plectognath fishes. - III. On Monacanthus setifer Bennett and related species, with a key to the genus Stephanolepis and descriptions of four new species. Annuals and Magazines of Natural History, series 11, 5(30): 518-535.

Hollard, H.L.G.M. (1854). Monographie des balistides. 3. Genre Monacanthus. Annales des Sciences Naturelles, Zoologie, serie 4, 2: 321-366

Hutchins, J.B. (1977). Descriptions of three new genera and eight new species of monacanthid fishes from Australia. Records of the Western Australian Museum 5: 3-58.

Hutchins, J.B. (1986). Review of the monacanthid fish genus Pervagor, with descriptions of two new species. Indo-Pacific Fishes 12: 1-35.

Hutchins, J.B. (1988). The comparative morphology and phylogeny of the monacanthid fishes. Unpublished PhD thesis, Murdoch University, Western Australia.

Hutchins, J.B. (1994). Description of a new genus and species of monacanthid fish from India. Records of the Western Australian Museum 16: 567-574.

Hutchins, J.B. (1997). Review of the monacanthid fish genus Paramonacanthus, with descriptions of three new species. Records of the Western Australian Museum, Supplement 54: 1-57.

Popta, C.M.L. (1900). On a small Monacanthus. Notes Leyden Museum 22:126-128.

Quoy, J.R.C. and Gaimard, J.P. (1824-1826). Voyage autour de Monde, entrepris par ordre du Roi, exécuté sur les corvettes de S.M. "l'Uranie" et "la Physicienne", pendant les années 1817, 1818, 1819, et 1820, par M. Louis de Freycinet. Poissons. Pillet Aîné, Paris. Pp. 192-401.

Regan, C.T. (1908). Report on the marine fishes collected by Mr. J. Stanley Gardiner in the Indian Ocean. Percy Sladen Trust Expedition. Transactions of the Linnaean Society of London (Zoology), Series 2, 12: 217-255.

Schlegel, H. (1850). Pisces. In Temminck, C.J. and Schlegel, H., Fauna Japonica. Von Siebold, P.F. (ed.), Leiden.

Tyler, J.C. (1970). An especially small, sexually dimorphic new species of filefish (Monacanthidae) from Australasian reefs. Proceedings of the Academy of Natural Sciences of Philadelphia 122: 273-290. 
Tyler, J.C. and Lange, M.D. (1982). Redescription of the Indo-Australian filefish Acreichthy; radiatus (Popta) (Monacanthidae, Tetraodontiformes). American Museum Novitates 2727: 1-14.

Whitley, G.P. (1943). Ichthyological descriptions and notes. Proceedings of the Linnaean Society of New South Wales 68: 114-144.

Woods, L.P. (1966). Family Aluteridae. In Schultz, L.P.,
Woods, L.P. and Lachner, E. A., Fishes of the Marshall and Marianas Islands. Volume 3. Families from Kraemeriidae through Antennariidae. United States National Museum Bulletin 202: 1-176

Manuscript received 3 July 2000; accepted 30 December 2001. 


\section{Guide to Authors}

\section{Subject Matter:}

Reviews, observations and results of research into all branches of natural science and human studies will be considered for publication. However. emphasis is placed on studies pertaining to Westem Australia. Longer papers will be considered for publication as a Supplement to the Records of the Westem Australian Museum. Short communications should not normally exceed three typed pages and this category of paper is intended to accommodate observations, results or new records of significance, that otherwise might not get into the literature, or for which there is a particular urgency for publication. All material must be original and not have been published elsewhere

\section{Presentation:}

Authors are advised to follow the layout and style in the most recent issue of the Records of the Westem Australian Muselum including headings, tables, illustrations and references.

The title should be concise, informative and contain key words necessary for retrieval by modem searching techniques. An abridged title (not exceeding 50 letter spaces) should be included for use as a running head.

An abstract must be given in full length papers but not short communications, summarizing the scope of the work and principal findings. It should normally not exceed $2 \%$ of the paper and should be suitable for reprinting in reference periodicals.

The International System of units should be used.

Numbers should be spelled out from one to nine in descriptive text; figures used for 10 or more. For associated groups, figures should be used consistently, e.g. 5 to 10 , not five to 10 .

Spelling should follow the Concise Oxford Dictionary.

Systematic papers must conform with the International Codes of Botanical and Zoological Nomenclature and, as far as possible, with their recommendations.

Synonymies should be given in the short form (taxon, author, date, page) and the full reference cited at the end of the paper. All citations, including those associated with scientific names, must be included in the references.

\section{Manuscripts:}

The original and two copies of manuscripts and figures should be submitted to the Editors, c/ Publications Department. Western Australian Museum, Francis Street. Perth, Western Australia 6000. They must be in double-spaced typescript on A4 sheets. All margins should be at least $30 \mathrm{~mm}$ wide. Tables plus heading and legends to illustrations should be typed on separate pages. The desired position for insertion of tables and illustrations in the text should be indicated in pencil. Tables should be numbered consecutively, have headings which make them understandable without reference to the text, and be referred to in the text.

High quality illustrations are required to size $(16.8 \mathrm{~cm} \times 25.2 \mathrm{~cm})$ or no larger than $32 \mathrm{~cm} \times 40$ $\mathrm{cm}$ with sans serif lettering suitable for reduction to size. Photographs must be good quality black and white prints, not exceeding $16.8 \mathrm{~cm} \times 25.2 \mathrm{~cm}$. Scale must be indicated on illustrations. All maps, line drawings, photographs and graphs, should be numbered in sequence and referred to as Figure/s in the text and captions. Each must have a brief, fully explanatory caption. On acceptance a computer disk containing all corrections should be sent with amended manuscript. The disk should be marked with program (e.g. Word, WordPerfect, etc).

In papers dealing with historical subjects references may be cited as footnotes. In all other papers references must be cited in the text by author and date and all must be listed alphabetically at the end of the paper. The names of journals are to be given in full.

\section{Processing:}

Papers and short communications are reviewed by at least two referees and acceptance or rejection is then decided by the editors.

The senior author is sent one set of page proofs which must be returned promptly.

The senior author will receive fifty free offprints of the paper. Additional offprints can be ordered at page proof stage. 


\section{Records of the Western Australian Museum Volume 21 Part 22002}

\section{CONTENTS}

\section{R.M. St Clair}

Western Australian Triplectidinae (Trichoptera: Leptoceridae): descriptions of the female of Triplectides niveipennis and larvae belonging to four genera
A. Reid
Western Australian Onychophora (Peripatopsidae): a new genus, Kumbadjena, for a southern species-complex

\section{K.J. McNamara and O.H. Melikov}

The asterostomatid echinoid Antillaster from the Paradash Group

(Middle Eocene) of the Nakhichevan Region of Azerbaijan

K.S.W. Campbell and R.E. Barwick

The axial postcranial structure of Griphognathus whitei from the Upper

Devonian Gogo Formation of Western Australia: comparisons with

other Devonian dipnoans

\section{E.M. Exley}

Bees of the Euhesma crabronica species-group (Hymenoptera:

Colletidae: Euryglossinae)

\section{J.B. Hutchins}

Description of a new genus and species of miniature monacanthid fish from the Seychelles and Marshall Islands 